\title{
A Mixed Integer Programming Model for Routing Containerships
}

Ching-Wu Chu

Department of Shipping and Transportation, National Taiwan Ocean University, Keelung, Taiwan 202., cwchu@mail.ntou.edu.tw

Tu-Cheng Kuo

Department of Shipping and Transportation, National Taiwan Ocean University, Keelung, Taiwan 202.

Jiing-Chang Shieh

Department of Shipping and Transportation, National Taiwan Ocean University, Keelung, Taiwan 202.

Follow this and additional works at: https://jmstt.ntou.edu.tw/journal

Part of the Business Commons

\section{Recommended Citation}

Chu, Ching-Wu; Kuo, Tu-Cheng; and Shieh, Jiing-Chang (2003) "A Mixed Integer Programming Model for Routing Containerships," Journal of Marine Science and Technology: Vol. 11: Iss. 2, Article 4.

DOI: $10.51400 / 2709-6998.2285$

Available at: https://jmstt.ntou.edu.tw/journal/vol11/iss2/4

This Research Article is brought to you for free and open access by Journal of Marine Science and Technology. It has been accepted for inclusion in Journal of Marine Science and Technology by an authorized editor of Journal of Marine Science and Technology. 


\title{
A MIXED INTEGER PROGRAMMING MODEL FOR ROUTING CONTAINERSHIPS
}

\author{
Ching-Wu Chu, Tu-Cheng Kuo, and Jiing-Chang Shieh
}

Key words: containership routing, mixed integer programming.

\begin{abstract}
In this paper, we formulate a mixed integer programming model for routing containerships. Our model helps in evaluating the optimal sequence of port calls and the number of containers transported between port pairs given the trip cycle time. Some numerical examples and a real world application of the Trans Pacific route are presented. The computational results show that our model, which solve the mixed integer programming optimally, is quite efficient and applicable to real world problem.
\end{abstract}

\section{INTRODUCTION}

A containership involves a major capital investment and the daily operating cost of a containership may amount to thousands of dollars. Proper selecting En route Ports and scheduling of containerships could yield great potential of improving their economic performance or cost savings.

Most liner shipping companies operating containerships assign a number of ships on a particular trade route fixed by two end ports and many en route ports.

The liner operation resembles a bus line-it publishes timetables and competes for cargo. Since the route of a containership, once determined, is difficult to change for a certain period of time, the routing decision should be made carefully after a thorough study. In order to adjust for changing environments, such as changes in freight rates, in cargo demand, in international regulations, or in operating cost, the liner shipping company should rearrange the route periodically. Based on the reasons mentioned above, it is worthwhile to formulate an analytic model solving the problem.

We conclude this section by presenting a survey

Paper Submitted 08/26/02, Accepted 06/12/03. Author for Correspondence: Ching-Wu Chu.

*Department of Shipping and Transportation, National Taiwan Ocean University, Keelung, Taiwan 202.

E-mail: cwchu@mail.ntou.edu.tw. of relevant work in this area. Many useful vehicle routing problems have been studied. A comprehensive survey can be found in Bodin et al. [3]. In contrast to vehicle routing, little work has been done in ship routing and scheduling. In the past, there have been attempts to solve ship routing and scheduling problems. Dantzig and Fulkerson [6] considered the first linear programming model, which minimizes the number of tankers to meet a fixed schedule. Flood [8] dealt with the same problem by minimizing the total distance in ballast, given a fleet size. The above two models are the pioneers of Operations Research applications in ship routing and scheduling.

Further extension of the above two models are considered by Briskin [5], Bellmore et al. [2], McKay and Hartney [10]. Baker [1], Stott and Douglas [18], and Fisher and Rosenwein [7] developed an interactive ship scheduling systems. There have been some papers on optimization models in sea transportation, but the majority have been on industrial carriers, bulk carriers, and tankers.

As to liner management, Boffey et al. [4] developed a heuristic model and an interactive decision support system for scheduling containerships on the North Atlantic route. Olson et al. [11] used a simulation model to obtain the medium range scheduling for a freighter fleet. Rana and Vickson [14, 15] presented nonlinear models. They tried to maximize total profit by finding an optimal sequence of ports of call for each ship. For solution, they presented Lagrangean relaxation and decomposition methods.

Perakis and Jaramillo [12], and Jaramillo and Perakis [9] formulated a linear programming model to minimize total fleet operating and lay-up cost during a planning horizon. Powell and Perakis [13] extended the work developed by Jaramillo and Perakis. An integer programming model is developed to minimize the operating and lay-up cost for a fleet of liner ships operating on various routes.

A complete survey of literaute on ship routing is presented in references [16] and [17]. The rest of this paper is organized as follows: The formal presentation 
of the model is explained in Section 2. Section 3 provides some numerical examples and illustrates some of the capabilities of the model applied to the Trans Pacific route. The final section concludes this paper.

\section{MODEL FORMULATION}

Most liner shipping companies operating containerships assign a number of ships on a particular trade route fixed by two end ports and many en route ports. Our model also restrict ourselves to this case.

\section{Model Assumptions}

The assumptions of our model are as the following: 1.It is not necessary to visit all the ports.

2.The ship changes direction at the starting (port 1) and the ending ports (port $\mathrm{n}$ ).

3.The operating costs at sea and at port are known.

4.the cargo is available at a uniform rate at each port.

\section{Decision Variables and Parameters}

The decision variables are defined as follows:

$X_{i j}$ : the number of containers transported from port $i$ to port $j$.

$Z_{i}= \begin{cases}1 & \text { if port } i \text { is visited in the outbound route } \\ 0 & \text { otherwise }\end{cases}$

$Z B_{i}= \begin{cases}1 & \text { if port } i \text { is visited in the inbound route } \\ 0 & \text { otherwise }\end{cases}$

$Y_{i j}= \begin{cases}1 & \text { if ports } i \text { and } j \text { are directly connected } \\ \text { in the outbound route }\end{cases}$

$Y B_{i j}= \begin{cases}1 & \text { if port } i \text { and } j \text { are directly connected } \\ \text { in the inbound route }\end{cases}$

Other parameters are defined as follows:

$n: \quad$ total number of ports in the network.

$P_{i j}$ : revenue charged per container for a port pair $(i, j)$.

$K_{i}$ : the operating costs at port $i$.

$C_{i j}$ : the operating costs at sea from port $i$ to port $j$.

$P D_{i j}$ : expected number of containers available to be transported from port $i$ to $j$, over the planning period.

$T_{i j}$ : travel time for a ship from port $i$ to port $j$. It is equal to the distance between port $i$ and port $j$, divided by the average ship's speed from port $i$ to port $j$.

$S P T_{i}$ : time stayed in port $i$ (including time required for the ship to load and unload at port $i$, plus pilotage time while leaving and entering harbour $i$.

$W: \quad$ the number of weeks allowed of a round trip (an integer number).

$S P \_L O A D$ : the shipload of a containership.

\section{Objective Function}

$$
\begin{aligned}
\operatorname{Max} Z & =\sum_{i} \sum_{j} P_{i j} X_{i j}-\sum_{i} K_{i} Z_{i}-\sum_{i} K_{i} Z B_{i} \\
& -\sum_{i} \sum_{j} C_{i j} Y_{i j}-\sum_{i} \sum_{j} C_{i j} Y B_{i j}
\end{aligned}
$$

The objective function maximizes the profit (revenue-operating costs). The constraints of the model are listed below:

\section{Departure Constraints}

$$
\begin{aligned}
& \sum_{j=i+1}^{n} Y_{i j}-Z_{i}=0(i=1, \ldots, n-1) \\
& \sum_{j=1}^{i-1} Y B_{j i}-Z B_{i}=0(i=2, \ldots, n)
\end{aligned}
$$

If a ship is not visiting the specific port $i$, the cargo cannot be transported. Constraint (1) and (2) ensure all possible departures from port i for outbound trip and inbound trip, respectively.

$$
\begin{aligned}
& \sum_{i=j+1}^{n} Y_{i j}=0(j=1, \ldots, n-1) \\
& \sum_{i=j+1}^{n} Y B_{i j}=0(j=1, \ldots, n-1)
\end{aligned}
$$

Constraint (3) and (4) prevent the ship from traveling in different direction for outbound trip and inbound trip, respectively.

\section{Arrival Constraints}

Constraint (5) and (6) enumerate all possible arrivals at port $i$ for outbound trip and inbound trip, respectively.

$$
\begin{aligned}
& \sum_{j=1}^{i-1} Y_{j i}-Z_{i}=0(i=2, \ldots, n) \\
& \sum_{j=i+1}^{n} Y B_{i j}-Z B_{i}=0(i=1, \ldots, n-1)
\end{aligned}
$$

\section{Capacity Constraints}

$$
X_{i j} \leq P D_{i j} Y_{i j}(i=1, \ldots, n-1 ; j=i+1, \ldots, n)
$$




$$
\begin{aligned}
& X_{i j} \leq P D_{i j} Y B_{i j}(i=1, \ldots, n-1 ; j=i+1, \ldots, n) \\
& \sum_{\text {possible } i, j} \sum_{i j} \leq S P_{-} L O A D \\
& (i=1, \ldots, n ; j=1, \ldots, n)
\end{aligned}
$$

In constraint (7), if $Y_{i j}$ equals to one, constraint (7) will be equal to $X_{i j} \leq P D_{i j}$. If $Y_{i j}$ is equal to zero, constraint (7) will be equal to $X_{i j} \leq 0$. By coupling two different cases together, we can ensure that the number of containers transported from port $i$ to port $j$ will be equal to zero or less than or equal to the expected number of containers available to be transported for outbound trip. With similar reasoning, constraint (8) imposes a similar restriction on $X_{i j}$ for inbound trip.

Constraint (9), applied to all port pairs, ensures that the total number of containers transported from any port $i$ to port $j$ ( $i<j$ for outbound trip; $i>j$ for inbound trip) will not exceed the ship's capacity.

\section{Connected Constraints}

$$
\begin{aligned}
& Z_{i}+Z_{j}-Y_{i j} \geq 0(i=1, \ldots, n-1 ; j=i+1, \ldots, n) \\
& Z_{i}+Z_{j}-2 Y_{i j} \geq 0(i=1, \ldots, n-1 ; j=i+1, \ldots, n) \\
& Z B_{i}+Z B_{j}-Y B_{i j} \geq 0 \\
& (i=j+1, \ldots, n ; j=1, \ldots, n-1) \\
& Z B_{i}+Z B_{j}-2 Y B_{i j} \geq 0 \\
& (i=j+1, \ldots, n ; j=1, \ldots, n-1)
\end{aligned}
$$

The inequalities in constraints (10) and (11) stand for the relationship between the port pair $(i, j)$ for outbound trip. By combining constraints (10) and (11), we can ensure that $Y_{i j}$ reprents whether port $i$ and $j$ are directly connected. Constraint (10) would be equal to one only if port $i$ and $j$ are directly connected. If port $i$ and $j$ are not directly connected, constraint (11) would force $Y_{i j}$ to equal zero.

The constraints (12) and (13) impose a similar relationship between port pair $(i, j)$ for inbound trip.

\section{Route Time Constraints}

$$
\begin{aligned}
& \sum_{i=1}^{n-1} \sum_{j=i+1}^{n} T_{i j} Y_{i j}+\sum_{i=j+1}^{n} \sum_{j=1}^{n-1} T_{i j} Y B_{i j}+\sum_{i=1}^{n} S P T_{i} Z_{i} \\
& +\sum_{i=1}^{n} S P T_{i} Z B_{i}-S P T_{n} Z B_{n} \leq 168 W \\
& (i=1, \ldots, n ; j=1, \ldots, \mathrm{n})
\end{aligned}
$$

There are 168 hours in one week and $W$ is an integer number. $168 \mathrm{~W}$ specifies the cycle time voyage in hours and the left hand side of constraint (14) ensures that the total time spend by a ship at sea and in harbor do not exceed the cycle time.

In general, the liner serves its customers based on weekly service. Once the cycle time is determined; the required vessels for operating will be known automatically. For example, if the cycle time is one week, one week trip needs only one vessel. If the cycle time is two weeks, a two-week trip needs two vessels.

\section{NUMERICAL EXAMPLE}

In order to demonstrate the applicability of our model, we first use an artificial data to provide some numerical examples and sensitivity analysis. Then, a real world application of the Trans Pacific route from Yang Mine Line in Taiwan is also presented. The detailed information of the artificial data (Tables 1-5) is listed as follows:

Both cycle time and shipload are main factors in route planning. First, we investigate the effect on the selection of En route ports by varying cycle time. The optimization software LINDO version 6.1 is used to solve our model. Figures 1-4 show the service routes under different cycle time. From Figure 1, we can see that all ports are visited. In this case, the cycle time is 7 weeks so that the liner shipping company needs 7 vessels for weekly service. By reducing the cycle time one week at a time, we can see that the number of ports visited and the total profit of each scenario (Table 6) with respect to cycle time are decreasing (Figures 2-4). It is clear that when the cycle time is not long enough (the company does not own enough containerships and does not intend to charter additional ships), the containership cannot visit all ports. From the above observations, we know that our model can help in selecting the optimal sequence of port calls.

Table 1. Stay time and operating cost at port (hour, \$)

\begin{tabular}{lrrrrrrrr}
\hline & \multicolumn{1}{c}{1} & \multicolumn{1}{c}{3} & \multicolumn{1}{c}{3} & \multicolumn{1}{c}{4} & \multicolumn{1}{c}{5} & \multicolumn{1}{c}{6} & \multicolumn{1}{c}{7} & \multicolumn{1}{c}{ ( } \\
\hline Stay time & 16 & 12 & 16 & 12 & 13 & 13 & 17 & 18 \\
Port charges & 1500 & 1000 & 1700 & 1100 & 1150 & 1400 & 1800 & 1950 \\
\hline
\end{tabular}


Table 2. Revenue charged per container between port pairs (\$/TEU)

\begin{tabular}{rrrrrrrrrr}
\hline & 1 & \multicolumn{1}{c}{2} & 3 & 4 & 5 & 6 & \multicolumn{1}{c}{7} & \multicolumn{1}{c}{ ( } \\
\hline 1 & 0 & 35 & 75 & 100 & 230 & 220 & 255 & 270 \\
2 & 30 & 0 & 50 & 100 & 198 & 170 & 215 & 280 \\
3 & 80 & 65 & 0 & 75 & 160 & 140 & 205 & 265 \\
4 & 115 & 105 & 65 & 0 & 45 & 120 & 260 & 300 \\
5 & 115 & 113 & 65 & 50 & 0 & 150 & 220 & 245 \\
6 & 220 & 195 & 130 & 120 & 90 & 0 & 70 & 90 \\
7 & 180 & 150 & 150 & 140 & 160 & 80 & 0 & 120 \\
8 & 200 & 210 & 185 & 210 & 165 & 90 & 50 & 0 \\
\hline
\end{tabular}

Table 3. Expected number of containers available to be transported between port pairs (TEU)

\begin{tabular}{rrrrrrrrr}
\hline & 1 & \multicolumn{1}{c}{2} & \multicolumn{1}{c}{3} & \multicolumn{1}{c}{4} & 5 & 6 & 7 & \multicolumn{1}{c}{ ( } \\
\hline 1 & 0 & 95 & 125 & 150 & 190 & 250 & 260 & 170 \\
2 & 110 & 0 & 80 & 130 & 160 & 210 & 190 & 210 \\
3 & 140 & 70 & 0 & 110 & 110 & 90 & 150 & 200 \\
4 & 190 & 140 & 50 & 0 & 85 & 90 & 120 & 170 \\
5 & 250 & 90 & 115 & 50 & 0 & 160 & 200 & 180 \\
6 & 220 & 95 & 140 & 130 & 210 & 0 & 80 & 95 \\
7 & 180 & 150 & 120 & 75 & 140 & 60 & 0 & 80 \\
8 & 120 & 140 & 120 & 110 & 105 & 80 & 40 & 60 \\
\hline
\end{tabular}

Table 4. The operating costs at sea between port pairs (\$)

\begin{tabular}{|c|c|c|c|c|c|c|c|c|}
\hline & 1 & 2 & 3 & 4 & 5 & 6 & 7 & 8 \\
\hline 1 & 0 & 36 & 100 & 144 & 168 & 200 & 258 & 286 \\
\hline 2 & 42 & 0 & 72 & 136 & 160 & 190 & 215 & 238 \\
\hline 3 & 108 & 80 & 0 & 80 & 100 & 106 & 156 & 192 \\
\hline 4 & 152 & 148 & 90 & 0 & 24 & 60 & 173 & 154 \\
\hline 5 & 180 & 172 & 112 & 30 & 0 & 42 & 141 & 174 \\
\hline 6 & 216 & 204 & 118 & 70 & 48 & 0 & 73 & 51 \\
\hline 7 & 250 & 207 & 151 & 168 & 135 & 67 & 0 & 49 \\
\hline 8 & 274 & 225 & 185 & 148 & 164 & 55 & 47 & 0 \\
\hline
\end{tabular}

Table 5. The traveling time at sea between port pairs (hour)

\begin{tabular}{|c|c|c|c|c|c|c|c|c|}
\hline & 1 & 2 & 3 & 4 & 5 & 6 & 7 & 8 \\
\hline 1 & 0 & 36 & 100 & 144 & 268 & 300 & 358 & 386 \\
\hline 2 & 42 & 0 & 72 & 136 & 260 & 290 & 315 & 338 \\
\hline 3 & 108 & 80 & 0 & 80 & 200 & 206 & 256 & 292 \\
\hline 4 & 152 & 148 & 90 & 0 & 224 & 260 & 273 & 254 \\
\hline 5 & 180 & 172 & 112 & 30 & 0 & 42 & 51 & 74 \\
\hline 6 & 216 & 204 & 118 & 70 & 48 & 0 & 35 & 51 \\
\hline 7 & 350 & 307 & 251 & 268 & 48 & 67 & 0 & 27 \\
\hline 8 & 374 & 325 & 285 & 248 & 64 & 51 & 27 & 0 \\
\hline
\end{tabular}


Next, we test the effects on the selection of En route ports by changing shipload. 800 TEU and 1000 TEU, two different capacities of shipload are tested and the cycle time of 7 weeks is used. From Figure 5, we can see that both cases have the same sequence of port calls.

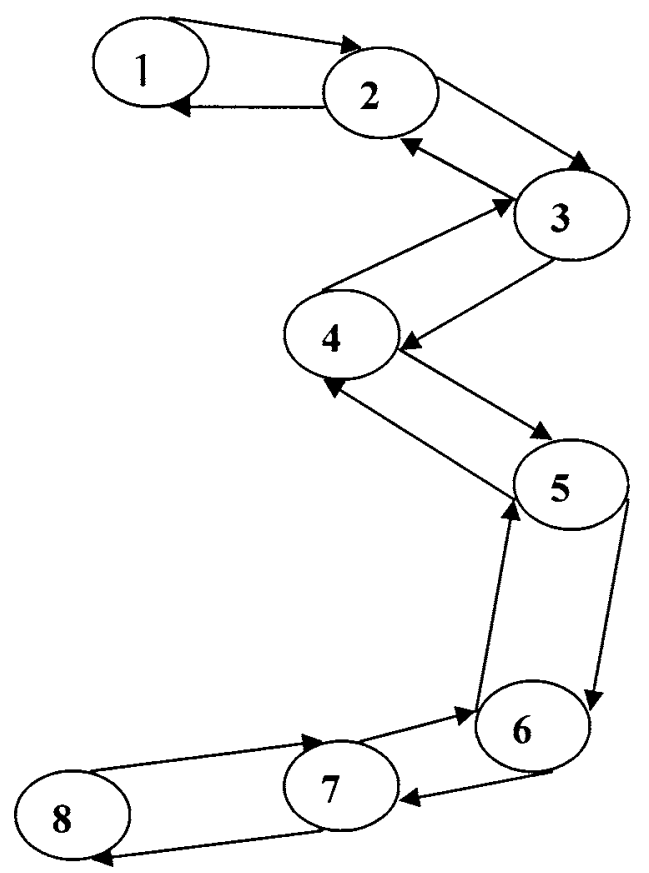

Fig. 1. Service route for cycle time 7 weeks and shipload 1500 TEU.

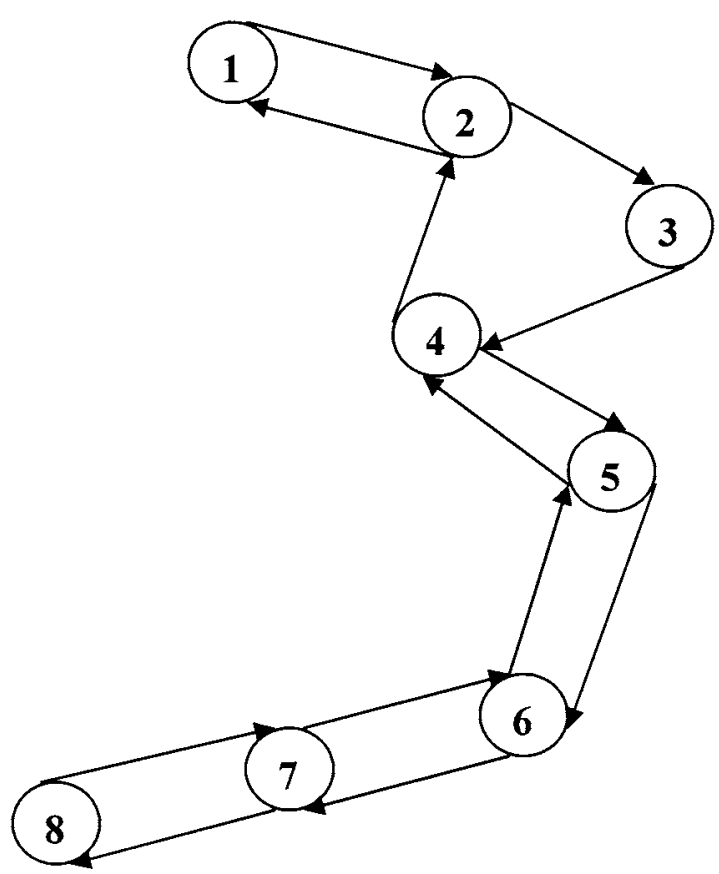

Fig. 2. Service route for cycle time 6 weeks and shipload 1500 TEU.
The main reason is that the liner shipping company wants to maximize its profit so all ports are visited while the cycle time is long enough. But if we look at Table 6 carefully, we can find that the numbers of containers transported between two cases are different. Based on

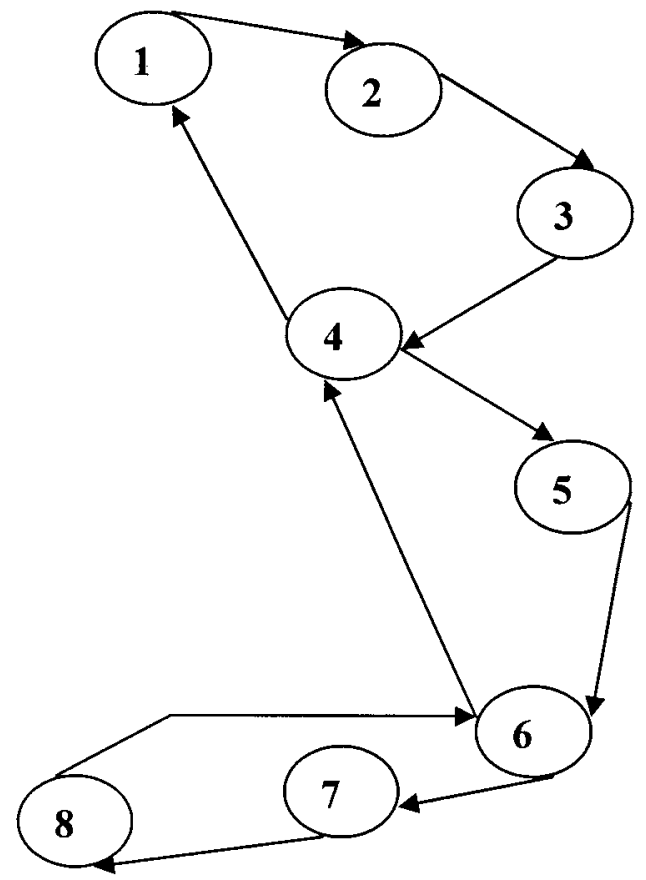

Fig. 3. Service route for cycle time 5 weeks and shipload 1500 TEU.

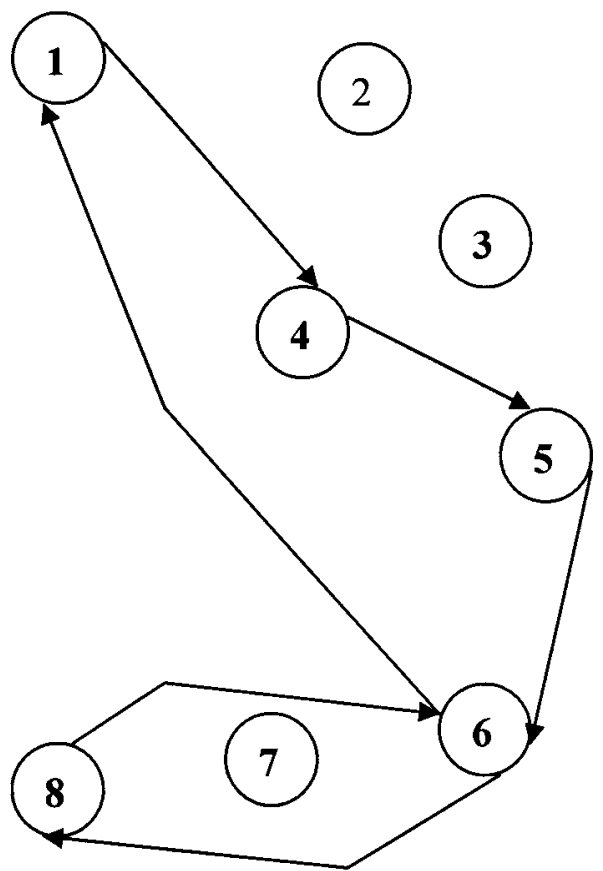

Fig. 4. Service route for cycle time 4 weeks and shipload 1500 TEU. 
Table 6. The number of container transported between port pairs under different cycle time and shipload

\begin{tabular}{|c|c|c|c|c|c|c|}
\hline & $\begin{array}{c}\text { TEU } \leq 1500 \\
\text { Cycle } \leq 7 \text { weeks }\end{array}$ & $\begin{array}{c}\text { TEU } \leq 1500 \\
\text { Cycle } \leq 6 \text { weeks }\end{array}$ & $\begin{array}{c}\text { TEU } \leq 1500 \\
\text { Cycle } \leq 5 \text { weeks }\end{array}$ & $\begin{array}{c}\text { TEU } \leq 1500 \\
\text { Cycle } \leq 4 \text { weeks }\end{array}$ & $\begin{array}{c}\text { TEU } \leq 800 \\
\text { Cycle } \leq 7 \text { weeks }\end{array}$ & $\begin{array}{c}\text { TEU } \leq 1000 \\
\text { Cycle } \leq 7 \text { weeks }\end{array}$ \\
\hline $1-2$ & 95 & 95 & 95 & 0 & 0 & 0 \\
\hline $1-3$ & 125 & 125 & 125 & 0 & 0 & 0 \\
\hline $1-4$ & 150 & 150 & 150 & 150 & 0 & 130 \\
\hline $1-5$ & 190 & 190 & 190 & 190 & 120 & 190 \\
\hline $1-6$ & 200 & 200 & 200 & 200 & 200 & 200 \\
\hline $1-7$ & 260 & 260 & 260 & 0 & 260 & 260 \\
\hline $1-8$ & 170 & 170 & 170 & 170 & 170 & 170 \\
\hline $2-3$ & 80 & 80 & 80 & 0 & 80 & 80 \\
\hline $2-4$ & 130 & 130 & 130 & 0 & 130 & 130 \\
\hline $2-5$ & 160 & 160 & 160 & 0 & 160 & 160 \\
\hline $2-6$ & 110 & 110 & 110 & 0 & 110 & 110 \\
\hline $2-7$ & 190 & 190 & 190 & 0 & 190 & 190 \\
\hline $2-8$ & 210 & 210 & 210 & 0 & 210 & 210 \\
\hline $3-4$ & 110 & 110 & 110 & 0 & 110 & 110 \\
\hline $3-5$ & 110 & 110 & 110 & 0 & 110 & 110 \\
\hline $3-6$ & 90 & 90 & 90 & 0 & 90 & 90 \\
\hline $3-7$ & 150 & 150 & 150 & 0 & 150 & 150 \\
\hline $3-8$ & 200 & 200 & 200 & 0 & 200 & 200 \\
\hline $4-5$ & 85 & 85 & 85 & 85 & 85 & 85 \\
\hline $4-6$ & 90 & 90 & 90 & 90 & 90 & 90 \\
\hline $4-7$ & 120 & 120 & 120 & 0 & 120 & 120 \\
\hline $4-8$ & 170 & 170 & 170 & 170 & 170 & 170 \\
\hline $5-6$ & 160 & 160 & 160 & 160 & 160 & 160 \\
\hline $5-7$ & 200 & 200 & 200 & 0 & 200 & 200 \\
\hline $5-8$ & 180 & 180 & 180 & 180 & 180 & 180 \\
\hline $6-7$ & 80 & 80 & 80 & 0 & 80 & 80 \\
\hline $6-8$ & 95 & 95 & 95 & 95 & 95 & 95 \\
\hline $7-8$ & 80 & 80 & 80 & 0 & 80 & 80 \\
\hline $8-1$ & 120 & 120 & 120 & 120 & 120 & 120 \\
\hline $8-2$ & 140 & 140 & 0 & 0 & 140 & 140 \\
\hline $8-3$ & 120 & 0 & 0 & 0 & 120 & 120 \\
\hline $8-4$ & 110 & 110 & 110 & 0 & 110 & 110 \\
\hline $8-5$ & 105 & 105 & 0 & 0 & 105 & 105 \\
\hline $8-6$ & 80 & 80 & 80 & 80 & 80 & 80 \\
\hline $8-7$ & 40 & 40 & 0 & 0 & 40 & 40 \\
\hline $7-1$ & 180 & 180 & 0 & 0 & 180 & 180 \\
\hline $7-2$ & 150 & 150 & 0 & 0 & 150 & 150 \\
\hline $7-3$ & 120 & 0 & 0 & 0 & 120 & 120 \\
\hline $7-4$ & 75 & 75 & 0 & 0 & 75 & 75 \\
\hline $7-5$ & 140 & 140 & 0 & 0 & 140 & 140 \\
\hline $7-6$ & 60 & 60 & 0 & 0 & 60 & 60 \\
\hline $6-1$ & 220 & 220 & 220 & 220 & 220 & 220 \\
\hline $6-2$ & 95 & 95 & 0 & 0 & 95 & 95 \\
\hline $6-3$ & 140 & 0 & 0 & 0 & 140 & 140 \\
\hline $6-4$ & 130 & 130 & 130 & 0 & 130 & 130 \\
\hline $6-5$ & 210 & 210 & 0 & 0 & 210 & 210 \\
\hline $5-4$ & 50 & 50 & 0 & 0 & 50 & 50 \\
\hline $5-3$ & 115 & 0 & 0 & 0 & 115 & 115 \\
\hline $5-2$ & 90 & 80 & 0 & 0 & 90 & 90 \\
\hline $5-1$ & 250 & 40 & 0 & 0 & 250 & 250 \\
\hline $4-3$ & 50 & 0 & 0 & 0 & 50 & 50 \\
\hline $4-2$ & 140 & 140 & 0 & 0 & 140 & 140 \\
\hline $4-1$ & 190 & 190 & 190 & 0 & 190 & 190 \\
\hline $3-2$ & 70 & 0 & 0 & 0 & 70 & 70 \\
\hline $3-1$ & 140 & 0 & 0 & 0 & 140 & 140 \\
\hline 2-1 & 110 & 110 & 0 & 0 & 110 & 110 \\
\hline PROFIT & 1147467 & 1047740 & 812226 & 324717 & 1108320 & 1144920 \\
\hline
\end{tabular}




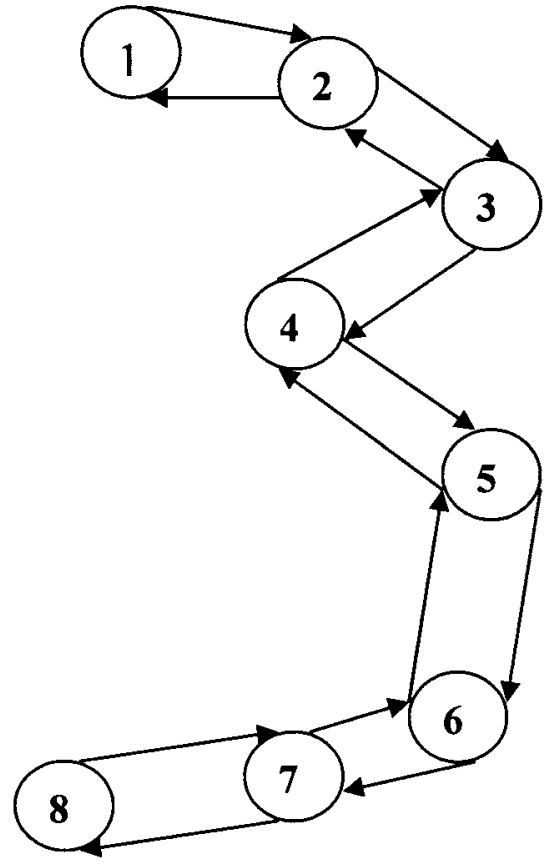

Fig. 5. Service route for cycle time 7 weeks and shipload 800TEU and 1000TEU.

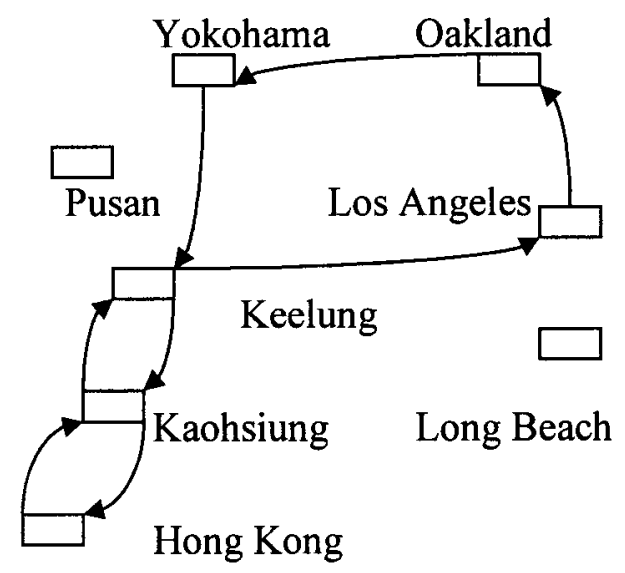

Fig. 6. Service route of Yang Ming Line.

the observations above, we know that our model can help in determining the optimal number of container transported between port pairs in different scenarios.

Finally, we use one of the Trans Pacific route provided by Yang Ming Line in Taiwan for testing our model. The service ports of Trans Pacific route in the United States include Los Angeles and Okaland. In the Asia ports, Hong Kong, Keelung, Kaohsiung and Yokohama are included (see Figure 6). Currently Yang Mine Line deploys 5 vessels with the capacities of 3500 TEU on this route for weekly service and the cycle

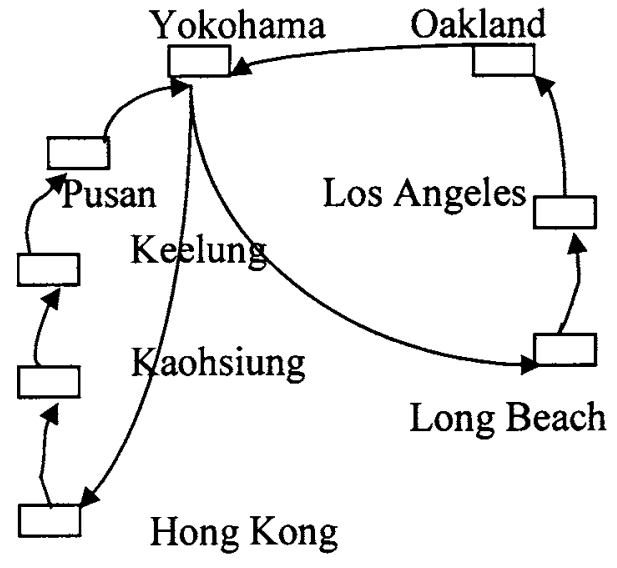

Fig. 7. Service route solved by our model.

time is 5 weeks.

We use the same cycle time to test the applicability of our model. The parameters are the same as those in Tables 1-5 and the real data are not shown here. Test result solved by our model is shown in Figure 7. By comparing two figures, we note that the ports called solved by our model are not identical to those by the Yang Ming Line.

Pusan, Yokohama and Long Beach are not included in the service ports of Trans Pacific route for outbound trip. After discussing with the route manager of the Yang Ming Line, we know that in order to provide better service level and increase competition ability, the Yang Ming Line opens three different routes to serve the customers in Asia and the United States of America. Pusan and Yokohama are currently served by another route.

The main reason for Long Beach is not visited is that the shipping company usually chooses only port to call in the neighboring area to cut down operating costs and shorten the cycle time. Since the distance between Long Beach and Los Angeles is not far away, containers can be transferred by land.

Though our model is applicable to real world problem and has taken main factors in routing into consideration, the route planning manager suggests that in a highly competition environment, a single route planning is not adequate for business decisions in the future. A more complicate network planning and even an expert system should be developed to facilitate in decision making.

\section{CONCLUSION}

In this paper, we have formulated a mixed integer programming model for routing containerships. Our model helps in evaluating the optimal sequence of port 
calls, the number of containers transported between port pairs given the trip cycle time. Our model is different from previous works in that our problem can be solved directly using optimization software and very quick in terms of time. Furthermore, once the cycle time is determined; the number of vessels needed for weekly service is known automatically. Based on this information, the liner shipping company can evaluate whether additional containerships should be chartered or not. An important topic for future research is an extension of single route planning to more complicate network planning.

\section{REFERENCES}

1. Baker, T.E., "Interactive Vessel Scheduling at Exxon," COR/TIMS/ORSA Joint National Meeting, Toronto, (1981).

2. Bellmore, M., Bennington, G. and Lubore, S., "A Multivehicle Tanker Scheduling Problem," Transport. Sci., Vol. 5, pp. 36-47 (1971).

3. Bodin, L., Golden, B, Assad, A., and Ball, M., "Routing and Scheduling of Vehicle and Crews: the State of the Art," Computers Operat. Res., Vol. 4, pp. 1-207 (1983).

4. Boffey, T.B., Edmond, E.D., Hinxman, A.I., and Pursglove, C.J., "Two Approaches to Scheduling Containerships with an Application to North Altantic Route," Operat. Res. Quarterly, Vol. 30, pp. 413-425 (1979).

5. Briskin, L.E., "Selecting Delivery Dates in Tanker Scheduling Problem," Manag. Sci., Vol. 12, pp. B224-233 (1996).

6. Dantzig, G.G. and Fulkserson, D.R., "Minimizing the Number of Tankers to Meet a Fixed Schedule," Naval Res. Logist. Quart., Vol. 1, pp. 217-222 (1954).

7. Fisher, M.L. and Rosenwein, M.B., "An Interactive Optimization System for Bulk Cargo Ship Scheduling," Naval Res. Logist. Quart., Vol. 36, pp. 27-42 (1989).
8. Flood, M.F., "Application of Transportation Theory to Scheduling a Military Tanker Fleet," Operat. Res., Vol. 2, pp. 150-162 (1954).

9. Jaramillo, D.I. and Perakis, A.N., "Fleet Deployment Optimization Model for Liner Shipping. Part 2: Implementation and Results," Maritime Policy and Management, Vol. 18, No. 4, pp. 235-262 (1991).

10. McKay, M.D. and Hartley, H.O., "Computerized Scheduling of Seagoing Tankers," Naval Res. Logist. Quart., Vol. 21, pp. 255-264 (1974).

11. Olson, C.A., Sorenson, E.E., and Sullivan, W.J., "Medium Range Scheduling for a Freighter Fleet," Operat. Res., Vol. 17, pp. 565-582 (1969).

12. Perakis, A.N. and Jaramillo, D.I., "Fleet Deployment Optimization Model for Liner Shipping. Part 1: Background, Problem Formulation and Solution Approaches," Maritime Policy Manag., Vol. 18, No. 3, pp. 183-200 (1991).

13. Powell, B. and Perakis, A.N., "Fleet Deployment Optimization for Liner Shipping: An Integer Programming Model," Maritime Policy Manag., Vol. 24, No. 2, pp. 183-192 (1997).

14. Rana, K. and Vickson, R.G., "A Model and Solution Alogrithm for Optimal Routing of a Time Chartered Containerships," Transport. Sci., Vol. 22, No. 2, pp. 8395 (1988).

15. Rana, K. and Vickson, R.G., "Routing Container Ships Using Lagrangean Relaxation and Decomposition," Transport. Sci., Vol. 25, No. 3, pp. 201-214 (1991).

16. Ronen, D., "Cargo Ships Routing and Scheduling: Survey of Models and Problems," Euro. J. Operat. Res., Vol. 12, pp. 119-126 (1983).

17. Ronen, D., "Ships Scheduling: The Last Decade," Euro. J. Operat. Res., Vol. 71, pp. 325-333 (1993).

18. Stott, K.L., and Douglas, B.W., "A Model-Based Decision Support System for Planning and Scheduling Ocean -Borne Transportation," Interfaces, Vol. 11, pp. 1-10 (1981). 